\title{
PEMANFAATAN PEKARANGAN MENJADI KEBUN SAYUR PRODUKTIF DI DAERAH PESISIR DI KECAMATAN WARA TIMUR.
}

\author{
Sitti Maryam Yasin ${ }^{1}$ dan Niken Nur Kasim ${ }^{2}$ \\ ${ }^{1}$ Email: st.maryamyasin@yahoo.co.id \\ Fakultas Pertanian Universitas Andi Djemma \\ ${ }^{2}$ Email: nikennurkasim@gmail.com \\ Fakultas Pertanian Universitas Andi Djemma
}

\begin{abstract}
Abstrak. Salah satu kecamatan pesisir laut di Kota Palopo adalah Kecamatan Wara Timur, Wilayahnya sebagian tambak dan masyarakat tinggal di rumah-rumah panggung yang dibawahnya terdapat air yang kadang pasang surut. Sebagian pekarangan cukup luas namun kondisi tanah yang berbatu dan berpasir tidak mampu dijadikan lahan yang subur, kondisi tanah yang salin tidak memungkinkan melakukan budidaya tanaman. Oleh karena itu, pemerintah dan perangkat desa setempat, warga, serta kaum ibu rumah tangga yang tergabung dalam kelompok Wanita Tani Mattirosompe dan kelompok wanita tani $\mathrm{Al}$, abrar di Kecamatan Wara Timur memikirkan program untuk memanfaatkan lahan pekarangan rumah agar lebih produktif untuk ditanami berbagai jenis sayuran. Berdasarkan hal tersebut maka masyarakat perlu diberi pengetahuan dan keterampilan membudidayakan tanaman secara vertikultur, yaitu model pertanaman vertikal dengan pot atau pipa, baik dengan menggunakan media tanah/konvensional atau dengan teknologi sistim hidroponik yaitu menanam tanpa menggunakan tanahTujuan yang ingin dicapai dari kegiatan ini adalah memberikan pengetahuan dan keterampilan bagi masyarakat pesisir tentang budidaya tanaman secara vertikultur dan hidroponik. Kelurahan Ponjalae dapat memproduksi sendiri berbagai jenis sayuran dari halaman pekarangan rumahnya, minimal untuk kebutuhan konsumsi keluarga sendiri, atau minimal mengurangi pengeluaran rumah tangga warga nelayan untuk membeli sayuran. Metode yang akan digunakan dalam budidaya tanaman secara vertikultur yang secara konvensional (menggunakan media tanah) dan sistem teknologi hidroponik dengan penyiraman dan hara otomatis. Jenis-jenis tanaman yang akan ditanam adalah kelompok tanaman hortikultura yaitu tanaman sayuran dan buah. Sebelum membudidayakan tanaman secara vertikultur dan hidroponik terlebih dahulu masyarakat akan diberi pelatihan agar masyarakat dapat melakukan secara baik dan benar sehingga tanaman dapat tumbuh dan berkembang dengan baik.
\end{abstract}

\section{Kata kunci: hidroponik dan sayuran}

\section{PENDAHULUAN}

Kota Palopo berada pada jalur tran sulawesi dengan jarak kurang lebih $367 \mathrm{~km}$ dari kota Makassar. Palopo merupakan salah satu dari sekian banyak daerah di Sulawesi Selatan yang memiliki potensi Sumber daya Alam yang paripurna, hal ini karena secara geografis palopo memiliki sumber-sumber ekonomi yang bersumber dari alam. Daerah Pengunungan, Dataran, dan Laut. Kota Palopo di bagian sisi sebelah Timur memanjang dari Utara ke Selatan merupakan dataran rendah atau Kawasan Pantai seluas kurang lebih $30 \%$ dari total keseluruhan, sepanjang pesisir pantai, yang merupakan kawasan permukiman kumuh yang basah dengan kondisi tanah genangan dan pasang surut air laut. Palopo dikenal sebagai sentra penghasil perikanan ikan laut, udang dan aneka hasil laut lainnya. Hal ini dikarenakan hampir 
separuh dari jumlah desa/kota di Kota Palopo terletak di wilayah pesisir dan merupakan penghasil berbagai jenis biota laut yang dapat diandalakan sebagai mata pencaharian utama penduduk desa secara tradisi.

Salah satu kecamatan pesisir laut adalah Kecamatan Wara Timur yang terdiri dari 7 (tujuh) kelurahan dengan luas wilayah $12,08 \mathrm{~km}^{2}$, wilayahnya sebagian besar merupakan tambak dan pemungkiman/perumahan penduduk. Kecamatan Wara Timur merupakan wilayah yang terpadat di Kota Palopo dengan kepadatan penduduk $2.649 \mathrm{jiwa} / \mathrm{km}^{2}$, dengan jumlah penduduk 35.988 jiwa (BPS, 2017). Ada dua kelurahan yang ada di Kecamatan Wara Timur sebagai mitra pada program PKM, yaitu mitra 1 kelurahan Salotellue yang merupakan daerah pertambakan dan kondisi tanah yang berbatu dan berpasir sehingga jarang tanaman tumbuh diakibatkan lahan yang kurang subur. Mitra ke dua yaitu, Kelurahan Ponjalae berada di sekitar pantai atau laut yang sebagian besar masyarakatnya bermata pencaharian sebagai nelayan. Umumnya masyarakat tinggal di rumah-rumah panggung yang dibawahnya terdapat air yang kadang pasang dan kadang surut. Jarak antar rumah satu dengan rumah lainnya sangat dekat yang dihubungkan dengan jalan jembatan yang terbuat dari kayu. Dengan kondisi demikian, sehingga sangat sedikit lahan yang bisa digunakan untuk pertanaman tanaman pertanian seperti sayuran, buah-buahan dan tanaman pangan, bahkan boleh dikatakan tidak ada. Kondisi ini sebetulnya hampir dialami semua desa di Kecamatan Wara Timur yang merupakan daerah pesisir dan pertambakan. Menurut mitra, kurangnya tanaman yang tumbuh di lingkungan pesisir menjadi salah satu faktor penyebab lingkungan pesisir terlihat gersang dan panas. Keterbatasan lahan dan tidak adanya media tanah yang baik untuk bertanam menjadi alasan masyarakat tidak melakukan penanaman. Komunitas masyarakat yang tinggal di daerah tersebut bermata pencaharian sebagai nelayan. Pendapatan mereka sangat ditentukan oleh hasil tangkapan dan produksi hasil tambak yang tidak menentu disebabkan karena berbagai faktor, diantaranya alat tangkap yang masih tradisional, areal penangkapan yang terbatas, maupun kondisi iklim yang tidak menentu. Dengan kondisi ekonomi sebagian masyarakat nelayan yang cenderung memiliki pendapatan rendah menyebabkan pemenuhan kebutuhan hidup keluarga terutama bahan pangan secara layak dan jumlah maupun kualitas sulit tercapai. Akan tetapi Pemenuhan pangan dan gizi yang cukup bagi masyarakat pada dasarnya tidak selalu harus dengan pendapatan yang tinggi karena banyak hal yang dapat dilakukan untuk mengatasinya. Salah satu cara adalah dengan memproduksi sendiri pangan di rumah tangga melalui usaha budidaya berbagai jenis sayuran sebagai sumber pangan dan gizi.

Kementerian Pertanian menyusun suatu konsep yang disebut dengan "Model Kawasan Rumah Pangan Lestari” yang dibangun dari Rumah Pangan Lestari (RPL) dengan prinsip pemanfaatan pekarangan yang ramah lingkungan untuk pemenuhan kebutuhan pangan dan gizi keluarga, serta peningkatan pendapatan yang pada akhirnya akan meningkatkan kesejahteraan. Komitmen pemerintah untuk melibatkan rumah tangga dalam mewujudkan kemandirian pangan perlu diaktualisasikan dalam menggerakkan lagi budaya menanam di lahan pekarangan, baik di perkotaan maupun di pedesaan. Di Kota Palopo pemanfaatan pekarangan belum optimal dan sebagian besar masih kosong. Oleh sebab itu pemerintah dan 
perangkat desa setempat, warga, serta kaum ibu rumah tangga yang tergabung dalam kelompok Wanita Tani Mattirosompe yang ada di Kelurahan Salotellue dan kelompok wanita tani Al, abrar di Kelurahan Ponjalae Kecamatan Wara Timur memikirkan program untuk memanfaatkan lahan pekarangan rumah agar lebih produktif untuk ditanami berbagai jenis sayuran.

Upaya ini tidaklah mudah, karena kondisi beberapa areal pekarangan rumah tangga tidak begitu bagus untuk pertanaman. Sebagian masyarakat tinggal di rumah-rumah panggung yang dibawahnya terdapat air yang kadang pasang surut, jarak antar rumah satu dengan rumah lainnya sangat dekat. Sebagian pekarangan cukup luas namun kondisi tanah yang berbatu dan berpasir tidak mampu dijadikan lahan yang subur, kondisi tanah yang salin tidak memungkinkan melakukan budidaya tanaman. Sebagian lagi areal pekarangan berbatasan langsung dengan pematang tambak. Selama ini pekarangan ditanami berbagai jenis tanaman sayuran atau bunga dengan kondsi yang tidak terawat. Oleh karena itu hal yang mungkin dilakukan adalah bagaimana memanfaatkan (mengoptimalkan) areal lahan atau pekarangan untuk menanam tanaman sayuran demi memenuhi kebutuhan keluarga. Berdasarkan kondisi dan hasil survei di lapangan maka model yang sesuai untuk pekarangan rumah di Kelurahan Salotellue dan Ponjalae adalah model vertikultur, yaitu model pertanaman vertikal dengan pot atau pipa, baik dengan menggunakan media tanah/konvensional atau dengan teknologi sistim hidroponik.

Sistem pertanian vertikultur adalah systim budidaya pertanian yang dilakukan secara vertical atau bertingkat. Sistem ini cocok diterapkan di lahan-lahan sempit atau di pemukiman yang padat penduduknya. Dengan metode ini, kita dapat memanfaatkan lahan semaksimal mungkin (Widarto, 1996). Hidroponik merupakan salah satu alternative bagi petani yang tidak memiliki lahan yang cukup untuk bercocok tanam (Ekawati 2005). Sistim hidroponik merupakan pengembangan ilmu pertanian yang dilakukan untuk mengembangkan sector pertanian guna terpenuhi kebutuhan manusia akan sayuran yang meningkat. Sejalan dengan adanya penemuan penanaman yang dilakukan tampa menggunakan tanah sebagai media tanam untuk bercocok tanam atau disebut dengan hidroponik (Wijayani,2005).

Secara teori taman sayuran merupakan contoh tanaman yang multifungsi. Di satu sisi tampilannya cukup memberikan kesan dan ketika dipanen dapat dimanfaatkan sebagai bahan pangan (Supriati, dkk 2008). Bahkan jika jumlahnya cukup banyak bisa dijual dan akan memberikan keuntungan ekonomis. Dengan tanaman sayur di pekarangan kita ikut mendukung gaya hidup hijau yang merupakan suatu usaha untuk mengatasi laju pemanasan global yang bisa dimulai dari pekarangan rumah (Ginting, 2010).

\section{PELAKSANAAN PENGABDIAN}

Metode pelaksanaan kegiatan Pengabdian Kemitraan Masyarakat pada kelompok wanita tani nelayan dilaksanakan dengan beberapa cara: (1) Sosialisasi (2) Pelatihan (3) Praktek dan (4) Pendampingan. 


\section{HASIL DAN PEMBAHASAN}

Kegiatan program kemitraan masyarakat pemanfaatan pekarangan menjadi kebun sayur produktif dilakukan pada daerah pesisir pantai yang terletak pada daerah Kelurahan Salotellue dan Kelurahan Ponjalae Kecamatan Wara Timur Kota Palopo. Kegiatan ini melibatkan dua mitra yaitu, Kelompok Wanita Tani Nelayan Al'Abrar di Kelurahan Salotellue dan Kelompok Wanita Tani... Kelurahan Ponjalae. Kegiatan PKM akan dilaksanakan bagi masyarakat sasaran yang dalam hal ini adalah kaum perempuan atau para istri nelayan. Jumlah masyarakat sasaran yang akan dilibatkan dalam kegiatan ini adalah 20 orang dan diharapkan saling bekerjasama dalam segala hal selama kegiatan berlangsung mulai dari tahap sosialisasi hingga tahap praktek/aplikasi.

Kegiatan ini dilakukan dengan beberapa tahap yaitu sebagai berikut;

1. Sosialisasi program ke masyarakat sasaran.

Tim pelaksana memperkenalkan program PKM ke masyarakat sasaran dan memberikan gambaran tentang kegiatan yang akan dilaksanakan sehingga masyarakat memahami dengan baik sehingga dapat berperan aktif dalam semua kegiatan.

2. Penyuluhan dan Pelatihan.

Metode pelatihan orang dewasa menempatkan peserta sebagai subyek pendidikan, sementara tutor berperan sebagai fasilitator. Yang aktif belajar adalah para peserta, sehingga dalam pelaksanaannya materi teoritis hanya diberikan sebagai pengantar, dilanjutkan denga materi praktik, diskusi dan sumbang saran. Penjelasan tentang materi oleh tutor hanya disampaikan di awal pertemuan sebagai panduan untuk memasuki materi praktik. Adapun jenis pelatihan yang diberikan kepada Mitra adalah sebagai berikut:

a. Penyuluhan

Kegiatan ini dimaksudkan untuk memperkenalkan kepada masyarakat tentang sistim budidaya pertanian yang tepat untuk lahan sempit atau lahan yang kurang subur. Selain itu masyarakan juga diajarkan bagaimana memanfaatkan pekarangan rumah menjadi kebun sayuran yang produktif dengan sistem teknologi pertanian yaitu teknologi hidroponik.

b. Pelatihan budidaya tanaman sayuran secara vertikultur dan sistem hidroponik.

Kegiatan ini dimaksudkan untuk memberikan pengetahuan dan keterampilan kepada masyarakat sasaran yang masih belum mengetahui tentang teknik budidaya atau bercocok tanam sayuran dengan sistem vertikultur/hidroponik yang dimulai dari pembuatan model intalasi hidroponik, cara penyemaian benih tanaman hidroponik, jenis tanaman yang sesuai dengan sistem vertikultur/hidroponik, persiapan penanaman, pemberian nutrisi pada tanaman serta penyiraman hara otomatis, pembuatan nutrisi organik, pengendalian hama dan penyakit, serta teknik pemeliharaan tanaman. 


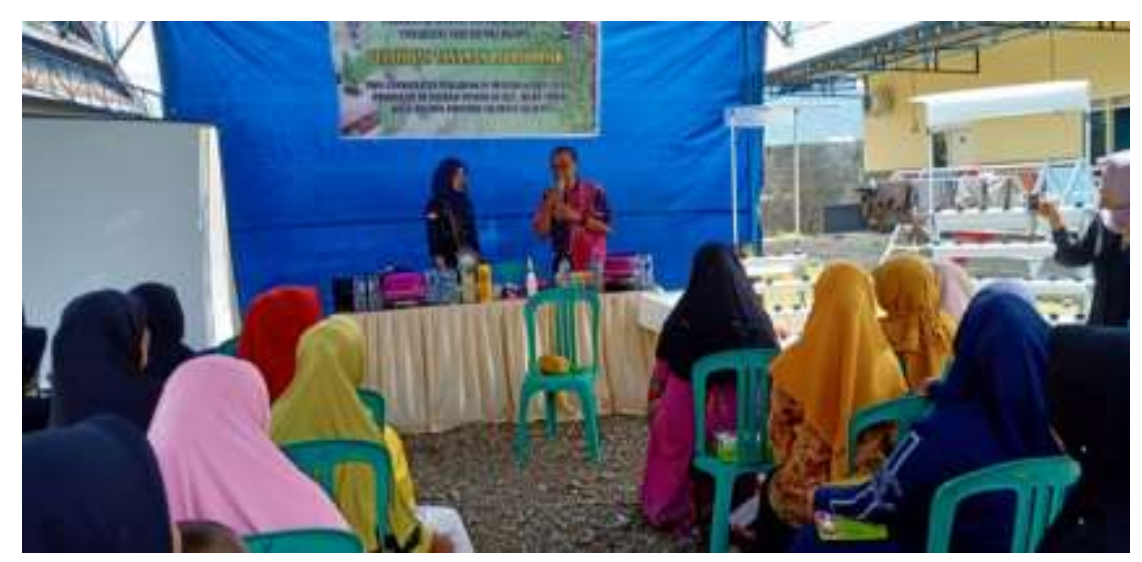

Gambar 1. Pelatihan Hidroponik

c. Pelatihan pembuatan pupuk cair untuk nutrisi hara pada tanaman hidroponik yang bahan-bahan yang digunakan adalah; air cucian beras, EM4, Kulit pisang, gula merah dan alat yang dipersiapkan adalah jerigen 5 liter, gelas ukur, pisau, ember dan selang.

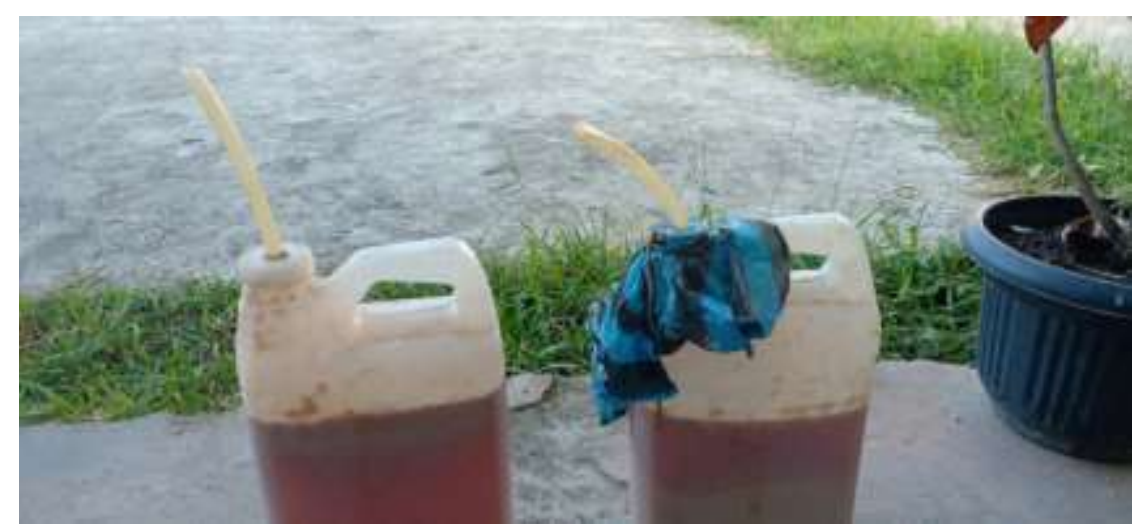

Gambar 2. Pupuk organik cair (POC)

d. Implementasi hasil pelatihan tanaman hidroponik dan pembuatan pupuk cair telah diaplikasikan di lapangan dan didampingan oleh tim pelaksana mulai dari penyemaian benih sampai pemeliharaan tanaman. Masyarakat sasaran yang telah mengikuti pelatihan akan mempraktikan cara budidaya berbagai jenis sayuran dengan sistem vertikultur konvensional dan hidroponik. Kegiatan pelatihan / praktek rancang bangun model vertikultur dan hidroponik dibuat demplot (percontohan) di rumah ketua kelompok. Sedang aplikasi budidaya sayuran secara vertikultur dilaksanakan dengan prinsip gotong royong. Model hidroponik yang diaplikasikan disesuaikan dengan ketersediaan bahan dan kondisi pekarangan rumah, sedang pemilihan jenis sayuran yang akan ditanam dimusyawarahkan dalam kelompok sehingga dalam satu kelompok terdapat berbagai jenis sayuran yang diusahakan. 
TO MAEGA Volume 1 Nomor 1, Agustus 2018, hlm : 1-7

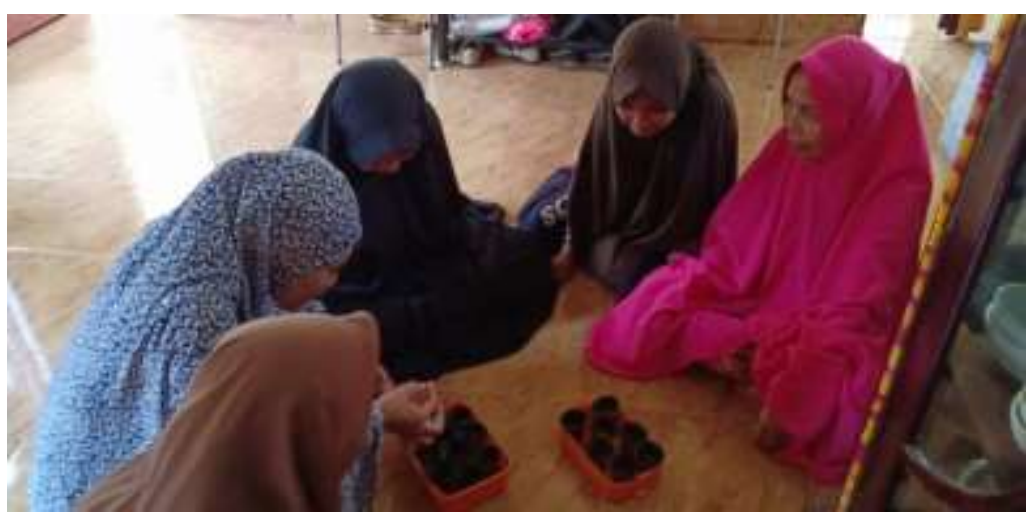

Gambar 3. Pendapingan penyemaian benih

Setelah mempraktikan budidaya tanaman secara vertikultur dan hidroponik akan terus mendapatkan bimbingan oleh tim pelaksana program melalui kegiatan pendampingan. Pendampingan dilakukan selama periode penanaman, pemeliharaan hingga panen sayuran dilakukan agar diperoleh hasil maksimal, dan untuk tahap selanjutnya diharapkan kelompok akan melakukannya secara partisipatif atau mandiri dengan membagi ilmu ke kelompokkelompok atau anggota yang lain.

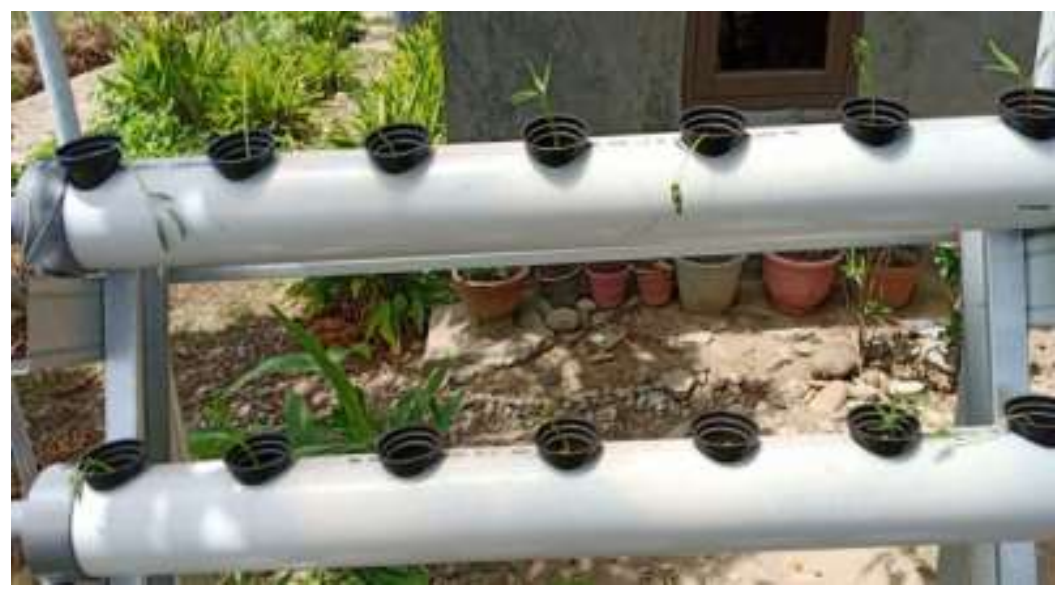

Gambar 4. Umur 2 minggu setelah tanam

\section{KESIMPULAN}

Kegiatan yang telah dilakukan dapat ditarik kesimpulan bahwa kegiatan pengabdian masyarakat yang dilakukan dapat menambah pengetahuan warga tentang memanfaatkan pekarangan rumah menjadi kebun sayuran yang produktif dengan sistem teknologi pertanian yaitu teknologi hidroponik.

\section{DAFTAR PUSTAKA}

Anonim, 2014. Palopo Dalam Angka Tahun 2014 Palopo Kota www.palopokota.go.id/content/uploads/.../palopo.../Palopo-Dalam-Angka-Tahun2014 diunduh 14 April 2017

BPS , 2017. Kota Palopo 2017. https://palopokota.bps.go.id/

Ekawati, E. 2005. Budidaya Tanaman Hidroponik. Jakarta: PT. Musi Perkasa 
P-ISSN: 2622-6332 \& E-ISSN: 2622-6340

TO MAEGA Volume 1 Nomor 1, Agustus 2018, hlm : 1-7

Ginting, M. 2010. Eksplorasi Pemanfaatan Pekarangan secara Konseptual Sebagai Konsep" Program Gerakan Dinas Pertanian Kota Pematangsiantar"http://musgin.wordpress.com/2010/03/27/pemanfaatan-pekarangan/ diunduh 14 April 2014.

Litban Pertanian, 2015. Pengembangan Kawasan Rumah Pangan Lestari. . www.litbang.pertanian.go.id/krpl/cover-krpl.pdf diunduh 12 Maret 2017

Prapanca., 2005. Bertanam Sayuran Organik di Kebun, pot dan Polibag. Jakarta: Penebar Swadaya.

Supriati, Y., Y. Yulia dan I. Nurlela, 2008. Taman Sayur + 19 Desain Menarik. Jakarta: Penebar Swadaya.

Widarto,L.1996. Vertikultur Bercocok Secara Bertingkat. Jakarta: PT. Penebar Swadaya

Wijayani, A., S.Priyanto. Peran Kalsium Terhadap Kualitas Pak Choi secara Hidroponik (dalam Seminar Nasional PERAGI), Yokyakarta

\section{UCAPAN TERIMA KASIH}

Kegiatan pengabdian masyarakat ini terlaksana melalui Program Mitra Masyarakat dan didanai oleh Kemenristik Dikti. 